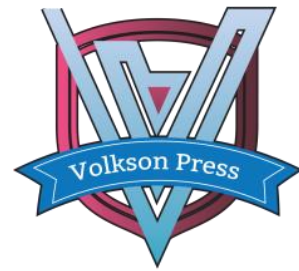

Contents List available at VOLKSON PRESS

Economics \& Management Innovations(EMI)

DOI : http://doi.org/10.26480/icemi.01.2017.229.230

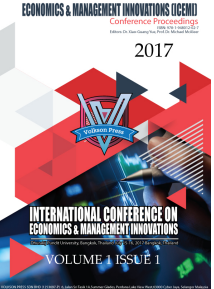

\title{
The Impact of Environmental Self-accountability on Green Consumption Behavior
}

\author{
Liu Hui-jun ${ }^{1^{*}}$, Chen Chun-shuo ${ }^{2}$, Liu Ling-jun ${ }^{3}$ \\ 1,2Dhurakij Pundit University, China-ASEAN International College, Bangkok, Thailand \\ ${ }^{3}$ Guangxi College of Sports and Physical Education, Guangxi, China \\ *email: 1amyliu7288@gmail.com \\ ${ }^{2}$ chencs0702@gmail.com \\ 3171206808@qq.com \\ This is an open access article distributed under the Creative Commons Attribution License, which permits unrestricted use, distribution, and reproduction in any \\ medium, provided the original work is properly cited.
}

\section{ARTICLE DETAILS}

\section{Article History:}

Received 02 october 2017

Accepted 06 october 2017

Available online 11 october 2017

\section{Keywords:}

Environmental

Self-

accountability, Theory of Planned

Behavior, Green Consumption

Behavior, Sharing Economy,

environmental protection.
ABSTRACT

A great upsurge of sharing economy occurs currently in China's green consumption market. On the basis of the theory of planned behavior, this research takes bike-sharing as an example to construct behavior structure model of green consumption by setting environmental self-accountability as a predictor of green consumption behavior and impression management and product attributes as the regulated variables. The results show that environmental self-accountability has positive impact on green consumption behavior. Green consumption tendency plays a role as intermediary. With the higher degree of consumer impression management, the positive impacts of environmental self-accountability to green consumption tendency will become stronger, otherwise weaker. The more the consumers recognize the hedonic attributes of products, the stronger the positive impacts of environmental self-accountability on green consumption tendency will be stronger, otherwise weaker. The conclusions also provide specific suggestions for the government and enterprises to find the right incentive to stimulate green consumption.

\section{Introduction}

\subsection{Background and significance of research}

Since the 1990s, when mankind recognized the importance of environmental protection, governments of different countries and environmental organizations had been committed to improve the environment and meanwhile they started to seek and expand the green consumer market. In the past two years, a business model of sharing economy had been developed in China and other countries."Use but not possession, idle is a waste" is not only a good interpretation of the sharing economy, but also the further refinement of green consumption. Green travel with the purposes of saving energy, reducing emissions and improving efficiency is regarded as a green consumption behavior. Psychological factors, which influence green consumption, like environmental self-accountability, environmental beliefs and environmental values, etc. have become the focus of human's attention as well apart from demographic characteristics, social or product factors and other factors.

At present, the research conclusions of green consumption are mostly originated from abroad. The theoretical model for the research of green consumption behavior has no unified standard, and it is built base on western country situation. Therefore, the research and practical application of green consumption in China need to consider the differences of national conditions, and it is necessary to explore a suitable green consumption behavior model for China's consumption market. This study takes into account the economic background, individual psychological factors, social factors and product factors as external regulatory factors. It has theoretical significance and enriches the relevant research of green consumption. At the same time, it has very high practical significance to help the government and enterprises to find endogenous power to push the green consumption. Then the consumers can really become new impetus of environmental protection and help to promote the green development.

Based on the perspective of social norms, using the personal norms as the predictors of environmental behavior, this study proposes and explains the definition of environmental self-accountability. This concept, which originated from the moral culture, is applied to the marketing field and extends to the green consumption area. It helps to explore the research model that suitable for the existing green consumption behavior in China, and expand the theoretical scope of this field. This paper focuses on the relationship between psychological mechanism and green consumption behavior. The selection of regulatory variables takes into account the characteristics of current business model. This study also makes up for the shortage of related research fields of green consumption and provides a better research perspective and new reference.

\section{Literature Review and Hypotheses Development}

Hines and Hungerford (2003) defined "pro-environmental behavior" as an act by which individuals or organizations to promote the sustainable or controlled use of natural resources. They emphasized that individuals stimulated by the concept of environmental protection should participate in environmental protection actively. In this paper, green consumption behavior is classified as a kind of environmental protection behaviors. Green consumption behavior is a human behavior which includes altruism and egoism and a kind of rational consumption habits.

Ajzen (1991) proposed the theory of planned behavior (TPB) which took behavioral attitude, subjective norm, perceptual control as the most important factors that affected individual behavioral intention and behavior. It was based on rational decision-making methods, which is often used to study consumer behaviors. Chan (1999) confirmed that consumers ' green consumption intention had strong predictive effect on their green buying behaviors, and the green consumption attitude of Chinese consumers was positive, and it was more likely to turn into green consumption intention. Self -standards included individual self - standard and normative self - standard(Stone \& Cooper, 2001). These norms can be internalized in some way to satisfy oneself rather than to please others. Self-accountability was a person's desire to live up to internal selfstandards (Peloza, 2013).

Environmental belief was an important psychological variable which was recognized by most scholars for predicting environmental behavior. They believed that positive environmental beliefs had significant effects on environmental behaviors. (Thogerson \& Olander, 2006). Moisande (2007) defined green consumption as a particular type of consumption behavior with more social awareness and social responsibility, and he believed that 
people would consider the consequences of their actions during consumption. Therefore, this paper argues that environmental selfaccountability and environmental beliefs are both the psychological variables which can predict pro-environmental behaviors. It contains an attribution of responsibility to oneself. It is people's desire of practicing environmental accountability when they are doing green behaviors and thinking whether it is beneficial or adverse to the environment or whether the individual should be responsible for that or not. whether the environmental self-accountability is activated or not might affect the green consumption behavior

$\mathrm{Wu}(2014)$ defined impression management as that people show themselves as pro-social individuals by purchasing green products in order to obtain status associated with pro-social behavior. And Voss (2003) had confirmed that the product contained two kinds of attributes: namely utilitarian attributes and hedonic attributes. People might have different preferences according to their perceived degree of product attributes. This was related to the psychological process. Decker (2010) also found that product attributes have a significant impact on consumer buying behavior. Based on the above, this paper may propose the following research hypotheses:

H1: Environmental self-accountability has positive influences on green consumption behavior.

H2: Environmental self-accountability will influence green consumption behavior through the green consumption tendency.

H3:With the higher degree of impression management, the positive influence of environmental self-accountability on green consumption tendency is stronger.

H4a:The higher consumers' recognition level of the product's utilitarian attributes is, the weaker the positive impact of environmental selfaccountability on the green consumption tendency will be.

H4b:The higher consumers' recognition level of the product's hedonic attributes is , the stronger the positive impact of environmental selfaccountability on the green consumption tendency will be.

\section{Methodology}

\subsection{Research framework}

China's green consumption market is currently facing a sharing economic boom. However, the previous research conclusions of green consumption are mostly originated from Western countries. The actual application of the research model needs to consider the national conditions. Therefore, this study will explore the practical application of the theory of planning behavior in Chinese context, especially the relationship between environmental self-accountability and green consumption behavior in the view of social norms, which might be influenced by impression management and product attributes. The theoretical framework of this study is drawn as follows :

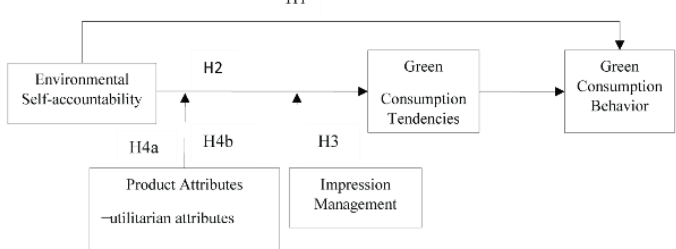

Figure 1. Research Framework

The general consumers were selected as the survey objects of this research, and the questionnaires were mainly completed on online by research objects from China. The questionnaires were issued in the late June 2017 until the end of June. Before the formal investigation, 30 questionnaires were issued and 30 valid questionnaires were collected. The reliability validity of the questionnaires was good, and the final actual distribution and recovery questionnaires were expected to be 600 . Descriptive statistical analysis is carried out first after data recovery. Meanwhile, the data is estimated by using SPSS19.0 and AMOS21.0 analysis software. The data includes the basic information of the sample, the correlation coefficient of the variables, the reliability and validity analysis, the fit of the structural equation model, the causality between variables, the path coefficients, and the mediating effect and the moderating effect of the variables.

\section{Expected research results and suggestions}

After the analysis of the data, the expected results of the hypothesis are fully supported, that is the environmental self-accountability has a significant positive impact on the green consumption behavior. The mediating effect of green consumption tendency has been verified and this conforms to the planned behavior theory which believes the intention has a strong explanatory power to the action. Meanwhile, when the consumers' impression management motivation and the recognition of product hedonic attribute become stronger, they will be more likely to arouse environmental self-accountability, and also be more inclined to conduct the green consumption behavior. It verifies the moderating effect of impression management and product attribute in relation. The results of the research can provide directions for the enterprises to grasp the consumers' demands, provide developing direction for product innovation and positioning, and stimulate the green consumption accurately and quickly.

According to the results, the government should pay more attention to the formulation and implementation of concrete and reasonable legal system norms to encourage green consumption. By doing these, consumers will gradually form good habits of green consumption thinking and behavior, so that the sustainable development outlook and green consumption can be deeply rooted in the hearts of people and gradually promote the green development pace.

Finally, the following research can be advanced from two points. One is to follow the market changes, with different green consumption business models to select different research objects to test the universality of the model. The second is that previous studies had mostly involved environmental behaviors in the private sector in the classification of environmental behaviors, but now enterprises are the important sources of pollution for a country. Therefore, this study will try to study the behavior type of organization behavior among environment protection, in other words, what kind of impact to the environment will appear when the individual does something through the organization they belong to, and what characteristics will rise when these happen in China.

\section{References}

[1] Hines, J. M., Hungerford, H. R., and Tomera, A. N. (1987). Analysis and synthesis of research on responsible environmental behavior: A meta-analysis. The Journal of environmental education, 18(2), 1-8.

[2] Ajzen, I. (1991). The theory of planned behavior. Organizational behavior and human decision processes, 50(2), 179-211.

[3] Chan, R. Y. (2001). Determinants of Chinese consumers' green purchase behavior. Psychology \& Marketing, 18(4), 389-413

[4] Stone, J. and Cooper, J. (2003). The effect of self-attribute relevance on how self-esteem moderates attitude change in dissonance processes. Journal of Experimental Social Psychology, 39(5), 508515.

[5] Peloza, J., White, K. and Shang, J. (2013). Good and guilt-free: The role of self-accountability in influencing preferences for products with ethical attributes. Journal of Marketing, 77(1), 104-119.

[6] Thøgersen, J. and Ölander, F. (2006). The dynamic interaction of personal norms and environment-friendly buying behavior: a panel study. Journal of Applied Social Psychology, 36(7), 1758-1780.

[7] Moisander, J. (2007). Motivational complexity of green consumerism. International Journal of Consumer Studies, 31(4), 404409.

[8] Wu, B., Li, D. J., and Xie, Z. X. (2014). A Study on the Influencing Factors of Consumers' Green Product Preferences. Soft science, 28(12), 89-94.

[9] Voss, K. E., Spangenberg, E. R., and Grohmann, B. (2003). Measuring the hedonic and utilitarian dimensions of consumer attitude. Journal of marketing research, 40(3), 310-320.

[10] Decker, R., \& Scholz, S. W. (2010). Determining the attractiveness of product attributes in consumer goods markets using POS scanner data. The Marketing Review, 10(3), 225-237. 